\title{
Level of Educational Development and the Underlying Disparities: A Study of Burdwan District, West Bengal.
}

\author{
Mr. Subhajit Ghatak \\ Assistant Teacher (Geography), Bijoypur Palsona High School (H.S.), Burdwan, W.B., India,
}

\begin{abstract}
Education plays significant role for human resource development as well as social development. So elementary education and basic education is necessary for any state or nation. Social inertia and infrastructural facility are the essential for systematic development of education. Lacking of this facility leads to inconsistency in the development of basic education. Poverty, early marriage system, poor infrastructural facility and employment opportunities are the factors which retards basic education development in different states of India. The forgoing analysis is an attempt to glean out the role of different for impaired development of basic education in Burdwan District, West Bengal.
\end{abstract}

Key words: Composite Z-score, Composite rank index, Drop out, Never-enrolled population, Sarva Siksha Mission.

\section{Introduction:}

Education has a significant role for human development as well as social development. The role of education for social development has been recognized ever since the days of Plato. Education, Plato believed, is indispensable for the economic health of a structured society, as education makes citizens 'reasonable men'. Since education has high economic value, Plato argued that a considerable part of the community's wealth must be invested in education. Major contribution relating to the relationship between education and economic growth was made first by Adam Smith, followed by a long honorable tradition of classical and neo-classical economists until Alfred Marshall (1890) who emphasized that "the most valuable of all capital is that invested in human beings". However, "in line with the biased postwar approach it was largely forgotten" (Myrdal, 1968, p. 167), and no systematic study on the contribution of education to economic growth could be found in the literature, until Schultz's (1961) Presidential Address to the American Economic Association in 1960, which created what is later aptly described as "human investment revolution in economic thought" (Bowman, 1966). Schultz's pioneering research followed by a mammoth growth of research in the area of Economics of Education, and the untiring research has clearly established that education is not merely a consumption activity, but for the most part an investment. It leads to the formation of human capital, comparable to physical capital, making a significant contribution to economic growth.

Synchronizing with the human investment revolution in economic thought, many countries around the world, and more particularly the newly independent developing countries expanded their educational systems and made heavy investments in education. The rates of growth of educational systems in many countries exceed the rates of economic growth. This is not surprising, as "during the process of economic modernization the rate of increase in human capital is higher than that of reproducible physical capital" (Schultz, 1986, p. 5). India stands as an outstanding classic example of massive expansion of educational systems among the third world countries. In the post-independent India, particularly since the inception of the plan era (since 1951), an educational explosion has taken place, which may be described as an "educational miracle". The 'miracle' is particularly important when one examines in the context of the colonial legacy.

After Independence, although, several plans and policies have been taken in India to drive out illiteracy completely, but the disparity and discrepancy exist in many dimensions. India's progress in providing access to quality and relevant education to its children and youth is a story of mixed results, with some remarkable outcomes and some nonstarters. While India can boast of contributing a large number of human resources to the pool of the world's most educated, scientifically and technically qualified people, it is equally appalling that the same country accounts for more than a third of the world's illiterates also(YOJANA:January,2010). This variation is mainly concerned with the inter- regional disparity in educational development. As for example, some of states namely Kerala, Tamilnadu, Himachal Pradesh have a higher literacy rates than traditionally backward states like Bihar, Rajasthan etc.

Present study is an attempt to unfold the disparity of education which includes the whole Burdwan district including its 31 blocks and 11 municipal areas, where the spatial variation regarding the educational attainment in upper primary level and its underlying disparity are analyzed. 
The major objectives of this paper are-

\section{Objectives:}

- To develop spatial variation of educational achievement and in the implementation of SSM in the Burdwan district.

- To find out the causes of such disparities.

- And finally to prescribed some suggestion for mitigating disparity.

\section{Methodology:}

Methodology adopted in this paper is quantitative in nature. Quantitative approach is mainly used in analyzing different parameters regarding educational development in upper primary level. Absolute and relative measure is unable to judge the uniformity of non-uniform indices or variables. So, realizing this critical situation $\mathrm{z}$-score and composite $\mathrm{z}$-score has been used to make a parity of judgement using the formulae given below:

\section{$\mathrm{Z}=(\mathrm{Xi}-\mathrm{Xm}) / \mathrm{SD}$}

Where, $\mathrm{Z}=\mathrm{z}$-score or standard score value,

$\mathrm{Xi}=$ actual value of individual unit,

$\mathrm{Xm}=$ arithmetic mean of the given number of data set,

$\mathrm{SD}=$ standard deviation of the given number of data set.

In unfolding the spatial variation in Burdwan district, block level infrastructural index (based on student-teacher ratio, no. of school per thousand of population and school-classroom ratio), enrolment index (based on the number of never enrolled population in respect of total population of 9-14 age group and enrolled population etc.) and drop out index (based on the number of drop out in respect of total population, total girls population and total backward population) has been used to judge the development or backwardness of educational performance. Here to find out the underlying causes of such disparities attempts has been made through sample survey of four villages from two blocks, namely Raniganj and Andal.

\section{Study Area:}

The study area includes 31 blocks of Burdwan districts which is one of the prosperous districts of West Bengal. The western part of the district is pronounced by urbanization with huge concentration of schools, where as the eastern part is prosperous agricultural area with relatively lower awareness of education (Fig-1).

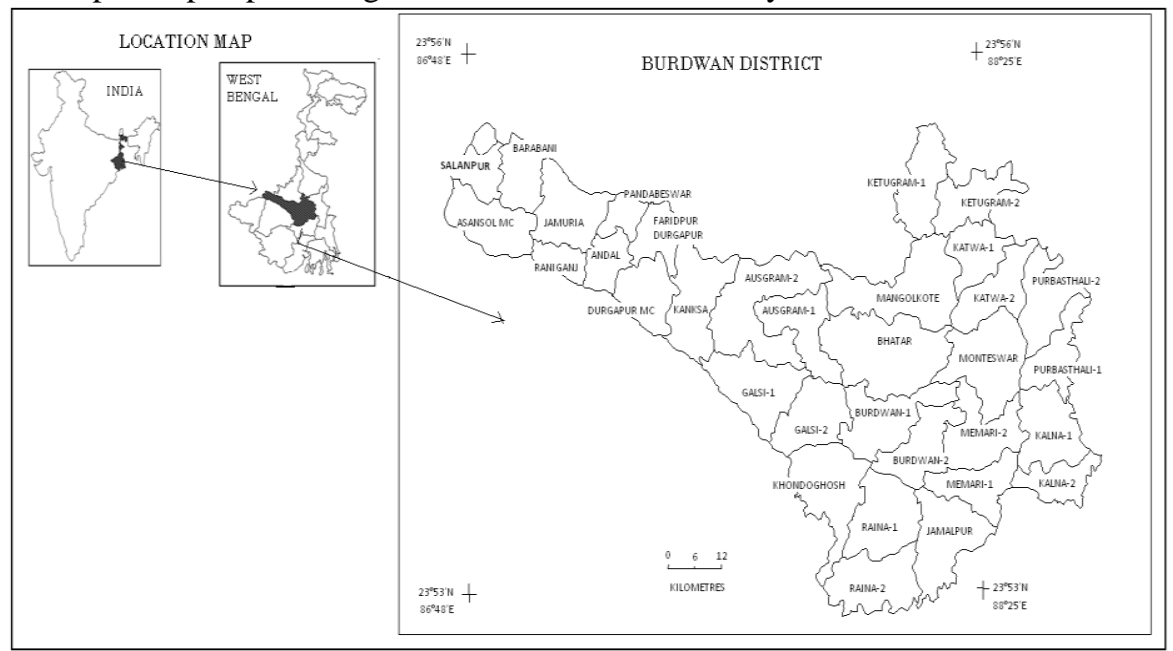

Figure-1: Location map of the study area.

\section{Elementary Education - A Brief:}

There has been a spectacular growth in elementary education in India during the post-independence period. Enrolments in elementary education have increased by seven times from 22.3 million in 1950-51 to 170 million in 2002-03. Official estimates on gross enrolment ratios have increased, from 42.6 per cent in primary and 12.9 per cent in upper primary education in 1950-51 to 96 per cent in case of primary education and 56 per cent in case of upper primary education by 2002-03, both of which together constitutes the Constitutional goal of universal elementary education. The overall gross enrolment ratio in elementary education was 81 per cent in 2002-03. The net enrolment ratio is estimated to be a little less than this. All this may represent a very significant growth in elementary education. But elementary education is also associated with very serious problems of high rates of dropout, high pupil-teacher ratio, poor quality of education, and low levels of student 

achievement. In sum, universalisation of elementary education, a goal set by the Constitution to be achieved within a ten-year framework, after the Constitution was framed, still eludes.

Secondary and higher education also experienced impressive quantitative growth: enrolments in secondary (including senior secondary) education have increased from 1.5 million in 1950-51 to 33 million in 2002-03. There were in 2002-03, 137 thousand secondary/senior secondary schools with about 1.8 million teachers. But despite seemingly impressive growth in enrolments, the size of enrolment is not proportionate to the population. For instance, only 35 per cent of the children of the age-group 14-17, according to official estimates, were enrolled in secondary education in 2002-03, compared to above 90 per cent in developed countries and 40-50 per cent in several developing counties. Inequalities by gender, caste and economic groups are high. Secondary education rarely serves as a meaningful effective terminal level of education. While India has made a significant progress in improving its literacy rates and has better literacy rates than other countries in South Asia(except Srilanka) and Sub-Saharan Africa, it is a major concern that it is still below the World and developing country average not only in literacy rates, but also in Gross Enrolment Ratio, Gender disparity and Infrastructural development.

\section{Development Of Education In Burdwan District:}

Burdwan is one of the developed districts of West Bengal regarding educational attainment, especially, in literacy rate. Although, it is observed that complete Literacy has not been achieved and this has far reaching socio-economic impacts. Enrolments in schools have improved substantially in recent years, mainly due to the significant implementation of SSM but the Retention rate is poor, and only a fraction of enrolled students completes even the Primary classes. Completions of Middle and Secondary levels are still lower. Substantial Gender biasness in both, access to and completion of education is a major cause of concern. Wide regional variation exists even within this sub-standard performance of the Basic Education system.

\subsection{Spatial Variation In Educational Attainment In Burdwan District:}

In studying the block level educational attainment of Burdwan district, three indicators namely, Infrastructure, Drop out and Never-enrolled Index appear to be more appropriate to understand spatial variation in educational attainment.

School infrastructure is perhaps the most important factor in relation to the standard of school education in rural as well as urban set up. Space for co-curricular activities, sufficient number of rooms for student's comfortability, teacher's attention all are directly or indirectly some reflection of infrastructural facility. So, good infrastructural setup obviously helps in attaining better educational standard. In case of Burdwan district, a significant disparity exists in terms of educational infrastructure (Fig-2). The two most developed blocks in terms of educational infrastructure in upper primary level are Raniganj (having an Index value of +4.55), Pandabeswar (+6.82). Other relatively developed blocks in this regards are Andal $(+2.2)$ Jamuria (+3.48), Memari-2 and Purbasthali-2. This spatial pattern mainly reflects the effect of urbanization process and the spread of urbanism. The western part of Burdwan district are the most urbanized, mining industrial belt and these facilitates better infrastructural development. On the other hand, Raina-2 (-3.79), Ausgram-1 \& 2 (-3.33\& -3.35), Bhatar (-2.10), Ketugram-1\&2 (+0.19\&-2.83), Monteswar (-3.42) and Memari1 have poor infrastructural facilities mainly because of their agriculture based ruralised structure of economy.

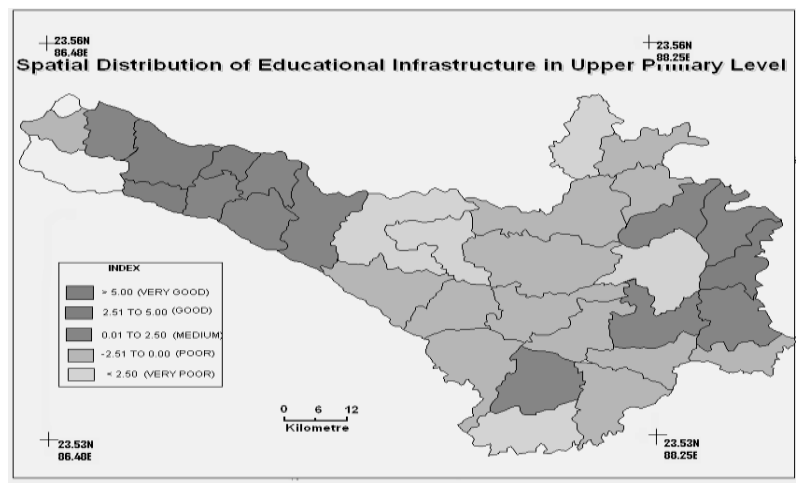

Figure-2: Distribution of infrastructural facilities in upper primary level.

The above mentioned spatial distribution in terms of school infrastructure clearly reflects the disparity in educational development. Not only disparity exists in terms of infrastructural expression, but also in the monetary funding and in implementation of plans and policies. 
Level of Educational Development and the Underlying Disparities: A study of Burdwan District,

Planning and development always consider two way measures-

a) To reduce the negative dimension; and

b) To enhance the positive dimension.

Perspective in such a measure is very much useful for educational development. Previous section is dealt with infrastructure as a measure of positive dimension and later section is turned with drop out should be considered eventually important for educational development, especially for the areas, where the dropout rate is high. Another important parameter regarding the educational attainment is the drop out measures. To study the spatial behavior of drop out in different blocks three sub parameters have been considered, these are the number of drop out in upper primary level per thousand of enrolled students, number of drop out girls in upper primary level per thousands of enrolled girls and drop out of backward students per thousand of backward enrolment. Considering the composite standard score index of drop out population, block Burdwan-1 \& 2 (-3.50\& -3.57 respectively) stands in higher footing than the other blocks of Burdwan (Fig-3). It obviously reflects that the parent of the mentioned region knows the importance of education and they are conscious to their child. On the other hand, the more industrialized and urbanized western blocks of Burdwan (Salanpur, Raniganj, Andal, Pandabeswar etc.) are poorer in drop out measures than the others. It is the Salanpur, which is poorest in drop out measures (having an Index value of +11.79 ).

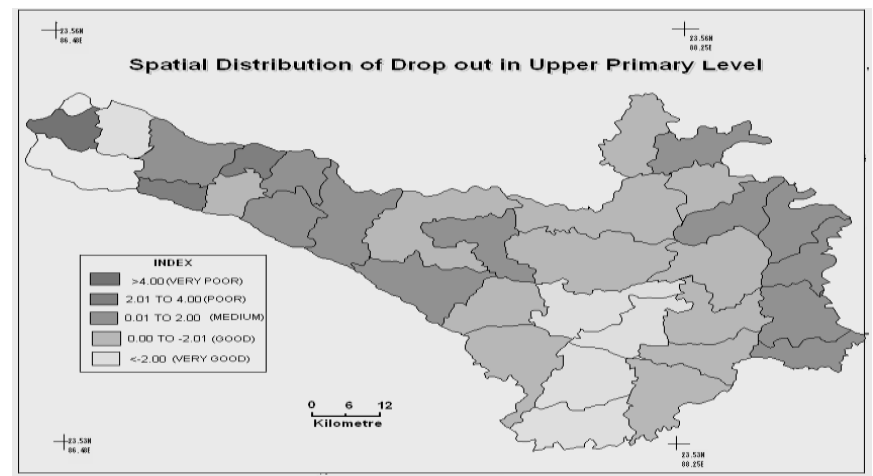

Figure-3: Distribution of drop out measures in upper primary level.

From the empirical survey of four villages (namely, Sahebganj, Nimcha of Raniganj block and Kajora, Dhandadihi of Andal block) of the said region, it is observed that, the poverty is the main factor behind the high rate of dropout. Besides, early marriage of the girls, low literacy, and various options of informal jobs especially, in mines and industries as a labor is also an important factor.

Among the sample survey of sixty households of the four villages, it is found that more than 20 cases (out of 56 cases) are due to the poverty and more than 15 cases are due to the marriage (Fig-4\&5). On the other hand, when we consider the income level as an important determinant of drop out, we find that, in most cases, dropout takes place in the families having poor economic base. Family with less than monthly income of Rs.3000 shows low dropout rate mainly because of illiteracy.
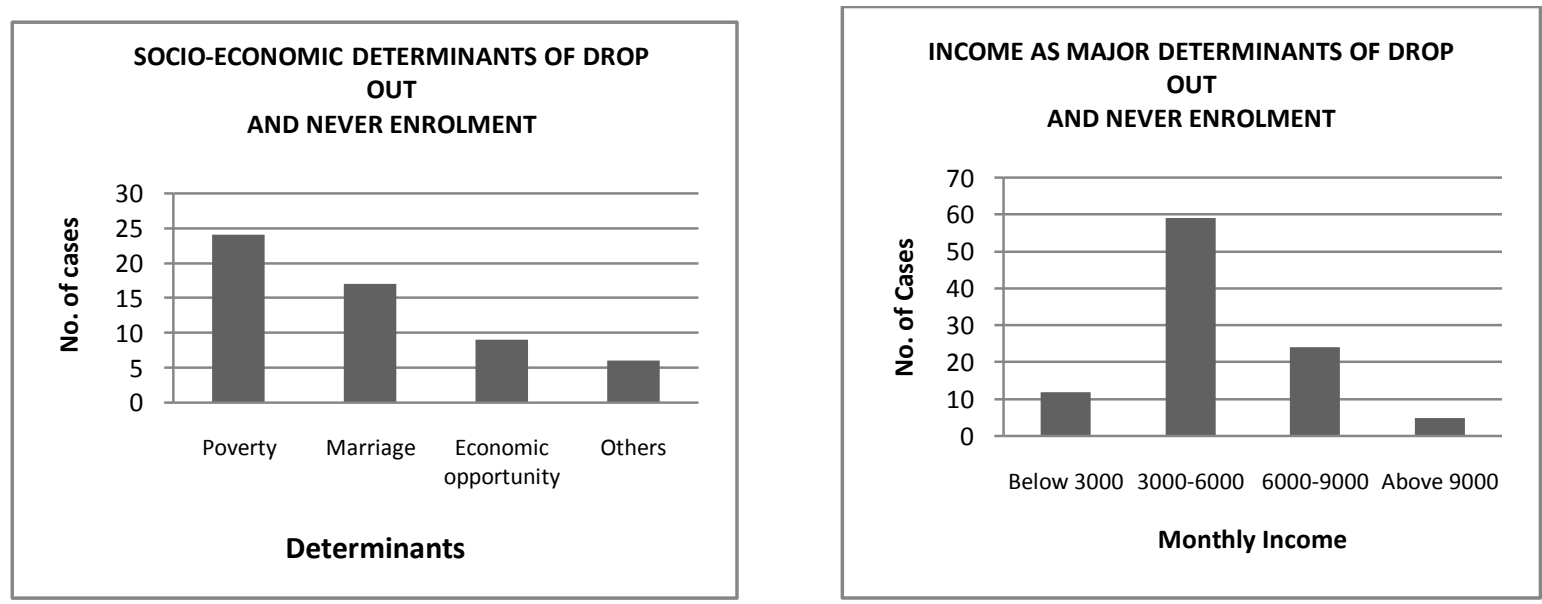

Figure-4\&5: Diagramatic representation of socio-economic determinants of Drop out \& Never enrolment.

Considering the never enrolment as an important parameter, sub parameters have been selected in the same way as of drop out index. Among the never enrolled child of 9 to 14 years of age group per thousands 
Level of Educational Development and the Underlying Disparities: A study of Burdwan District, population of that age group, it is observed that the Jamuria block has the highest and Burdwan-2 has the lowest number of never enrolled. In both case of girls enrolment and backward enrolment, Raina-2 has the lowest scored never enrolled population and the highest loading are recorded at the Jamuria and Memari-2 respectively (Fig-6).

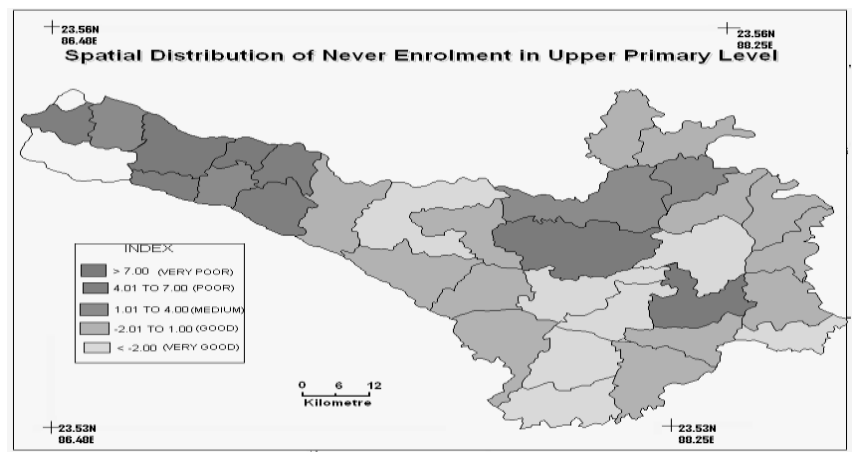

Figure-6: Distribution of Never enrolled population in upper primary level in Burdwan districts.

The poverty, social structure and persistent cultural backgrounds of the family are the most important determinants of never enrolment. But in case of girls' enrolment, gender biasness, ignorance towards the female child, and early marriage are important factors.

Composite never enrolled index shows that the Jamuria (+7.77), Memari-1(+6.12), Pandabeswar $(+4.64)$ and Bhatar (+4.17) stands in the higher footing than others, indicating a very demoralized conditions in terms of educational attainment. It might be due to any of the above mentioned causes that play the role. On the other hand, Raina-2 (-3.06), Ausgram-2 (-2.07), Burdwan-1 \& 2 (-2.80\&-2.55 respectively), Kalna-2 (-2.08) and Monteswar (-2.69) are the blocks characterized by low never enrolled population.

After the three types of measures it is necessary to make an assemblage of the three segregated aspects which will be able to put a concrete picture about the spatial variation. Composite Rank Index of the Z-score value of the given parameters is considered to be the best way to do so. According to the Composite Rank Index (Fig-7), it is observed that the developed blocks (as per ranking) regarding over all educational development are Burdwan-1 \& 2(composite rank 23.5 and 25 respectively), Galsi-2(32), Barabani (33.5) and Raina-2(35). It is the Salanpur (72), Bhatar (65), Galsi-1(62.5) and Jamuria (60) which are at the lowest rank.

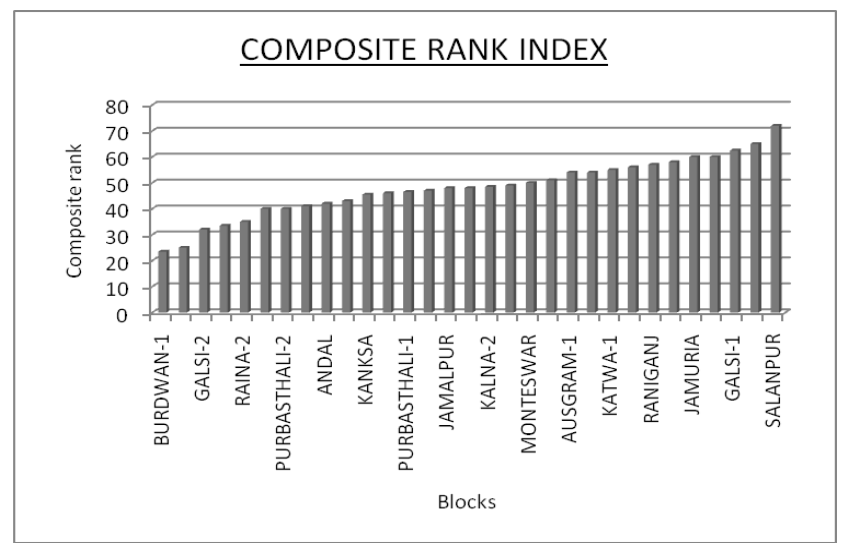

Figure-7: Diagramatic representation of block wise educational attainment through Composite rank.

\section{Recomendations:}

After all some specific planning and implementation is necessary to overcome the barriers of school education like the better implementation of SSM, especially, in case of infrastructural attainment is required. Other than this, more monetary funding is necessary for the blocks which are in poor condition regarding infrastructural setup. To reduce the drop out, specifically in the western blocks, several encouraging plans and policies should be implemented with better management; such as Mid-day Meal, various types of scholarships, recreational facilities etc. Employment opportunities are the best aspect of education in every level. So, various types of job options after the upper primary level should be initiated, especially through the generation of various vocational courses, so that students are encouraged in attaining schools. More than that, better awareness among the common people and socio-economic reforms is required, not only for the educational development but for the all round development process. 
Level of Educational Development and the Underlying Disparities: A study of Burdwan District,

\section{Conclusion:}

Betterment of any society, in terms of education, requires some degree of modification in particular and socio-cultural reforms in general. Most of the blocks in the Western Burdwan are developed in infrastructure but lacking in educational attainment due to lack of awareness. Social motto must be changed with some positive as well as encouraging measures by which school education will achieve a drastic change. For some eastern blocks, infrastructural development is immediate step for augmenting better and balanced school education.

APENDIX-1

\begin{tabular}{|c|c|c|c|c|}
\hline \multirow[t]{2}{*}{ SL.NO. } & \multirow[t]{2}{*}{ BLOCKS } & \multicolumn{3}{|c|}{ COMPOSITE Z-SCORE VALUE ON } \\
\hline & & $\begin{array}{c}\text { INFRASTRUCTURAL } \\
\text { INDEX }\end{array}$ & $\begin{array}{l}\text { DROP OUT } \\
\text { INDEX }\end{array}$ & $\begin{array}{c}\text { NEVER ENROLLED } \\
\text { INDEX }\end{array}$ \\
\hline 1 & ANDAL & 2.2 & -1.02 & 1.4 \\
\hline 2 & AUSGRAM-1 & -3.33 & 0.52 & -0.43 \\
\hline 3 & AUSGRAM-2 & -3.35 & -1.91 & -2.07 \\
\hline 4 & BARABANI & 1.55 & -3.11 & 0.4 \\
\hline 5 & BHATAR & -2.10 & -1.06 & 4.17 \\
\hline 6 & BURDWAN-1 & -0.47 & -3.50 & -2.8 \\
\hline 7 & BURDWAN-2 & -1.49 & -3.57 & -2.55 \\
\hline 8 & DURGAPUR-FARIDPUR & 1.65 & 1.37 & 2.21 \\
\hline 9 & GALSI-1 & -1.77 & 0.74 & -1.17 \\
\hline 10 & GALSI-2 & -0.31 & -2.40 & -1.68 \\
\hline 11 & JAMALPUR & -1.49 & -0.68 & -1.95 \\
\hline 12 & JAMURIA & 3.48 & 0.79 & 7.77 \\
\hline 13 & KALNA-1 & 0.86 & 3.06 & -1.15 \\
\hline 14 & KALNA-2 & -0.97 & 0.77 & -2.08 \\
\hline 15 & KANKSA & 0.61 & 0.74 & -1.79 \\
\hline 16 & KATWA-1 & -2.13 & -0.71 & 0.08 \\
\hline 17 & KATWA-2 & -1.29 & 0.35 & -1.11 \\
\hline 18 & KETUGRAM-1 & 0.19 & -1.70 & -1.50 \\
\hline 19 & KETUGRAM-2 & -2.83 & 1.05 & -1.99 \\
\hline 20 & KHANDOGHOSH & -0.70 & -1.12 & -1.78 \\
\hline 21 & MEMARI-1 & -1.19 & -1.51 & 6.12 \\
\hline 22 & MEMARI-2 & 2.15 & -1.57 & -1.54 \\
\hline 23 & MONGALKOTE & -2.23 & -1.41 & 1.69 \\
\hline 24 & MONTESWAR & -3.42 & -0.64 & -2.69 \\
\hline 25 & PANDABESWAR & 6.82 & 5.28 & 4.64 \\
\hline 26 & PURBASTHALI-1 & 1.55 & 0.32 & -0.65 \\
\hline 27 & PURBASTHALI-2 & 3.23 & 0.38 & -1.23 \\
\hline 28 & RAINA-1 & 1.03 & -2.34 & -2.73 \\
\hline 29 & RAINA-2 & -3.79 & -3.15 & -3.06 \\
\hline 30 & RANIGANJ & 4.55 & 4.52 & 3.23 \\
\hline 31 & SALANPUR & -0.26 & 11.79 & 3.35 \\
\hline
\end{tabular}

\section{References:}

\section{Journal Papers:}

[1] YOJANA (2010, January), INDIA CELEBRATING 60 YEARS,

[2] Tilak_India_PBET_WP6_final, http://www.cas.ed.ac.uk/PBET.html.

[3] Mukherjee, Dipa., (2004), EDUCATIONAL ATTAINMENT IN INDIA : TRENDS, PATTERN AND Policy Issues = http://mpra.ub.uni muenchen.de/4869.

[4] Kingdon Gandhi, Geeta., (2007), THE PROGRESS OF SCHOOL EDUCATION IN INDIA, Website: http://www.gprg.org/

[5] BOOKS:

[6] Goel S.C., (1975), EDUCATION AND ECONOMIC GROWTH, The Macmillan Company of India Limited, Delhi.

[7] DISE-2008-09, District of Burdwan, West Bengal. 